\title{
Models for Optimization of Supply Chain Network Design Integrating the Cost of Quality: A Literature Review
}

\author{
Lamiae Douiri*, Abdelouahhab Jabri, Abdellah El Barkany \\ Faculty of Sciences and Techniques, Mechanical Engineering Laboratory, Sidi Mohammed Ben Abdellah \\ University, Fez, Morocco \\ Email: "lamiae_iad@yahoo.fr, abdelouahhab.jabri@usmba.ac.ma, a_elbarkany2002@yahoo.fr
}

Received 10 May 2016; accepted 9 August 2016; published 12 August 2016

Copyright (C) 2016 by authors and Scientific Research Publishing Inc.

This work is licensed under the Creative Commons Attribution International License (CC BY). http://creativecommons.org/licenses/by/4.0/ (c) (i) Open Access

\begin{abstract}
After focusing on Cost of Quality (CoQ), the companies must now move into integrating the CoQ into Supply Chain upstream and downstream, to address $\operatorname{CoQ}$ issues across Supply Chain Network Design (SCND) modeling. In this preliminary study, we propose a state of the art of the published works on models and classifications of SCND incorporating the CoQ existing in the literature. In the second part of this paper, we will present a review by studying and analyzing the application of some meta-heuristics to solve supply chain models. The reviewed meta-heuristics include: the genetic algorithm (GA), and simulated annealing (SA). Finally, we suggest directions for future research.
\end{abstract}

\section{Keywords}

Cost of Quality, Supply Chain Management, Multi-Objective Optimization, Genetic Algorithm, Simulated Annealing

\section{Introduction}

The current market trends show that is the Supply Chain (SC) that competes and not only the company. All the entities of supply chain from suppliers to end user could systematically affect the supply chain effectiveness. Thus, there should be close cooperation between all entities to strengthen the SC value. In the present business environment, where quality is a crucial competitive factor, providing high quality products or services is becoming a goal of all Supply Chains. Measuring the Cost of Quality (COQ) in the SC context is considered as a

\footnotetext{
${ }^{*}$ Corresponding author.
} 
key performance measurement tool to examine supply chain performance in monetary terms. The CoQ approach gives a way to reconcile organizations two objectives which are conflicting: maximizing quality and minimizing cost, and then to have one objective: the cost of quality minimization. Based on the literature in 1950s, Juran [1] and Feignebaum [2] were the first authors who demonstrated the necessity of measurement of CoQ. Since then, many researchers proposed quality cost models, methods and techniques, to estimate the CoQ into the SC.

There is no single definition of CoQ and its elements [3], nor a single model to identify and control the costs of quality. In 1991, the British Standards Institution defined CoQ as the sum of the costs incurred by prevention and evaluation activities plus the internal and external failures. Mashowski and Dale [3] have defined the CoQ by the sum of the costs of conformance plus the costs of nonconformance, where the cost of conformance is the price paid to prevent poor quality (ex.: inspection and appraisal), and the cost of nonconformance is the cost of the poor quality caused by the failure of the product or the service to meet customer requirements (ex.: rework, scarp), and all other costs paid in order to achieve a good quality product or service. According to Srivastava [4] who gives the first step towards estimating CoQ in a Supply Chain (SC), COQ is considered as the sum of the losses incurred across a supply chain to prevent poor quality, to ensure and evaluate that the quality requirements are being met, and any other costs due to poor quality. Botoroff [5] adds that COQ systems are regarded today as an essential tool in managing quality and the quality authorities, as for example ASQC (American Society for Quality Control) have incorporated the CoQ into their certification programs. A practical question that arises is how do managers currently conceive the impact of the cost of quality on their enterprise? A total cost of quality have been estimated by Crosby [6] at $20 \%-35 \%$ of sales for manufacturing and service companies, by Feigenbaum [2] at $10 \%$ of revenues [7] and it is around $30 \%$ of total manufacturing costs [4]. As observed by Altiparmak et al. [8] in a supply chain network (SCN), managers need to make strategic decisions that are viable for the business to reduce costs and maintain profit margins while the quality is kept at pre-specified level, through a multi objective optimization of Supply Chain Network Design (SCND). Several studies have been conducted to optimize SCND problems, and there has been a growing interest of using evolutionary algorithms to solve these problems. Farahani et al. [9] proposed a bi-objective supply chain model for the distribution network. The objective functions were: minimizing costs and minimizing backorders of products. The solution was found by applying evolutionary algorithms. Castello-Villar et al. [10] designed and optimized a capacitated Supply Chain Networks including quality measures, the author developed evolutionary algorithms to solve the model that could assist firms in improving their profitability and quality simultaneously.

The remainder of this paper is organized as follows: the first section provides a study background on Cost of Quality models, section 2 presents references having described, analyzed and developed several models of SCND considering the cost of quality, and the rest of the article treats the application of some evolutionary algorithms like Simulated Annealing (SA) and Genetic Algorithm (GA) to solve supply chain models.

\section{Cost of Quality Models: Review}

In this section we will present a literature review on different COQ models. COQ models have been developed first by Feigenbaum [2], and Freeman [11]. Soon after, many researchers have suggested different approaches to measure the CoQ. Most CoQ models are based on the P-A-F classification: prevention (P), appraisal (A) and failure (F) costs [2] [3] [12], due to its universal acceptance amongst quality organizations and researchers. However, as Shiffauerova and Thomson [13] suggested, the P-A-F classification is not the only category accepted, since other models found in the literature can be discussed and used. Shiffauerova and Thomson [13] have classified CoQ models into four categories: P-A-F or Crosby's model, opportunity cost models, process cost models and ABC Approach (activity based costing).

\subsection{PAF or Crosby's Model}

The well-known PAF classification was developed by Feigenbaum [2]. Later, Joseph Juran [1] proposed the graphical form of the CoQ model and the concept of quality costing. According to Porter and Rayner [14], this model supposes that more investment in prevention and appraisal activities will reduce failure costs and total quality cost. Most of Quality authorities have adopted the P-A-F model, as the American Society for Quality Control (ASQC) in 1970 and the British Standard Institute (BSI) in 1990, and it is employed by many organizations which use quality costing.

Campanella [15] defined each category of the PAF classification as follows. 


\subsubsection{Prevention Costs}

Prevention Costs are the costs associated with any activity to avoid poor quality in products and services. Example of prevention costs: System development, Quality engineering, training, Statistical process control (SPC), planning, implementation and controlling quality system in the organization.

\subsubsection{Appraisal Costs}

Appraisal Costs are the costs engaged to ensure the conformance of products and services to predefined specifications. Example of Appraisal costs: Test and inspection of purchased materials, Final product testing and inspection, Supervision of inspecting activities, Maintenance of test equipment.

\subsubsection{Internal Failure Costs}

Internal Failure Costs are the costs resulting from the nonconformance of product and service to the predefined specification before delivery or shipment of the product or service to the customer. Example of Internal failure costs: Cost of scrap, Rework, Reinspection and Retesting of reworked products, Down time caused by quality problems, Analysis of the cause of defects in the production, Debugging software errors.

\subsubsection{External Failure Costs}

External Failure Costs are costs of nonconformance to the predefined specification after the product or service has been delivered to the customer. Example of External failure costs: Product recalls, Repairs and replacements beyond the warranty period.

External failure costs cannot be tolerable when they are not desirable and catastrophic for customer's safety and sustainability (for example: aerospace, pharmaceutical, and food industries). In this direction, a growing interest is granted to provide high level of quality, safety and traceability [16].

The problem is to define which element can be classified as a cost of quality and to differentiate it from the other costs. Akyoun et al. [17] proposed an algorithm as described in Figure 1, which helps managers to identify quality costs and separate them from other costs occurring in manufacturing plants:

\subsection{Classical View and Modern View of CoQ}

The classical view illustrated in Figure 2, a quality cost behavior in the P-A-F model was firstly proposed by Juran [1]. This model suggests that, with higher quality levels, the internal and external failure costs decrease, while the costs of appraisal and prevention costs increase. As appraisal costs rise, failure costs tend to fall. This is because more failures are discovered at an earlier stage. In a manufacturing environment, it costs less to reject faulty material at the goods inward stage than it does to scrap a manufactured item that has had the faulty material incorporated into it [14].

According to Juran's interpretation, the resulting cost minimum of the total cost function, represent the optimal level of quality.

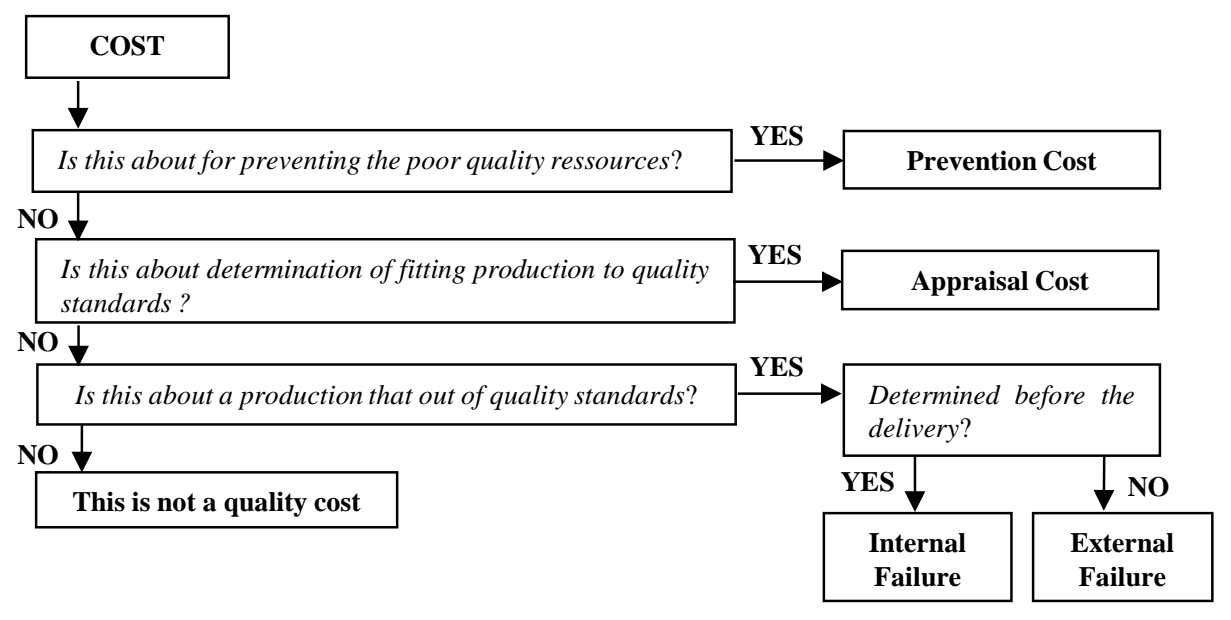

Figure 1. Determination and classification of the quality costs [17]. 


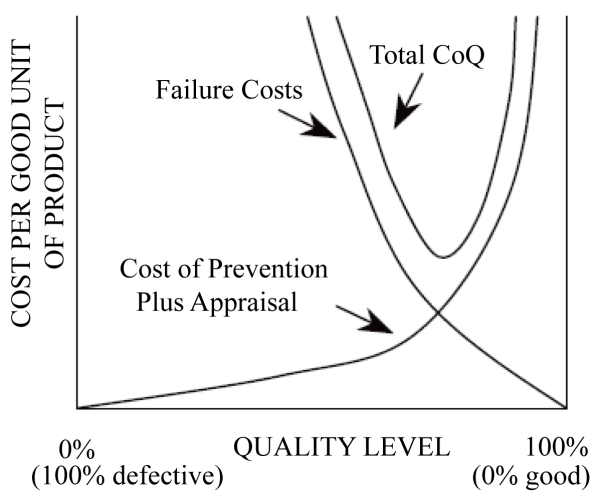

(a)

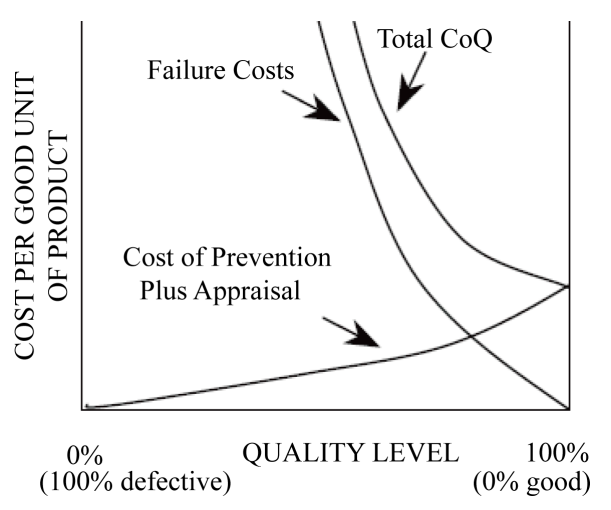

(b)

Figure 2. (a) Classical view and (b) modern view [13].

Many references support the classical view, for example: Fox [18]; Price [19], etc.

However, the view of old CoQ is in conflict with current trends in industry to strive for best possible quality. The new CoQ model presented in Figure 2, (b) is more in agreement with empirical findings from industry. For this model, the total cost curve is negatively sloped and the cost optimum shifts to the perfect quality level.

The main difference between the two models is the fact that $100 \%$ quality of conformance can be reached at a finite cost in the modern model. In general, it is accepted that the new COQ model presents a much more rounded perspective on quality costs and seems to reflect business reality much closer than the classical model.

\subsection{Opportunity Cost Model}

Many researchers have considered opportunity or Intangible costs as hidden or indirect costs which occur when organization losses customers because of defective product that reaches the market [20].

Carr [21] included opportunity costs in CoQ measurement. Albright and Roth [22] also recognize the importance of intangible costs. They applied Taguchi loss function to estimate indirect quality costs that cannot be calculated directly. Other authors [12] studied intangible costs and found that these costs result on more than 83\% of the total loss in revenue and about 56\% of loss in profit. As shown in Figure 3, the Opportunity cost model trend would be similar to the modern view of CoQ model when the opportunity costs are considered.

\subsection{Process Cost Model}

Process cost model was first developed by Ross [23]. He proposed a computer program to calculate process cost but this program was convenient only for manufacturing environment. Marsh [24] used first the process cost model for CoQ measurement as an alternative of the PAF model. The process cost integrates the cost of conformance (CoC) and the cost of nonconformance (CoNC) based on individual processes.

The mean objective of process cost model is to calculate the quality costs of each process in order to increase or decrease required prevention investment for each process for new design development. Many researchers have highlighted the process cost model advantages to ease the categorization and the analysis of direct and indirect quality cost. According to Vaxevanidis et al. [25] the process cost model can be applied to both service and manufacturing industries and it is useful in businesses which implement total quality management programs. The structure of the process cost model is presented in Figure 4.

\subsection{Activity Based Costing (ABC) Model}

Activity Based Costing (ABC) is an approach classification of costs based on their processes and activities. It was developed by Cooper and Kaplan [26] from Harvard Business School as an alternative method that can be used to classify costs. Tsai [27] was the first who proposed a method to measure CoQ using the ABC approach, this method aims at classifying and extracting costs of various activities in the process and eliminates activities with non-adding value (Figure 5).

Table 1 summarizes the classification of CoQ models into the four groups previously described, and present some examples of publications developing the models. 


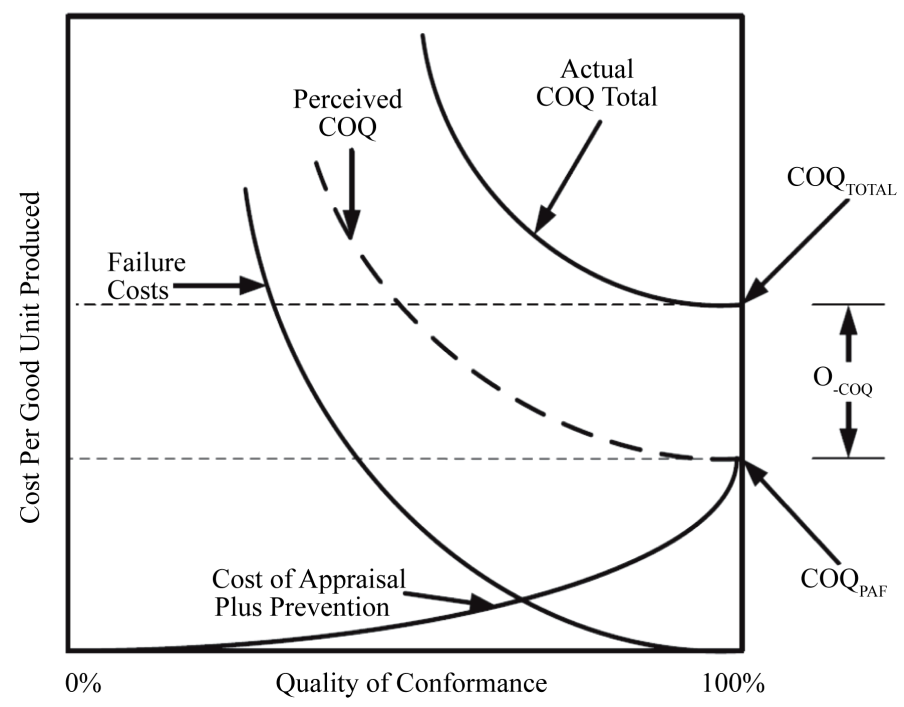

Figure 3. Total COQ considering opportunity costs [12].

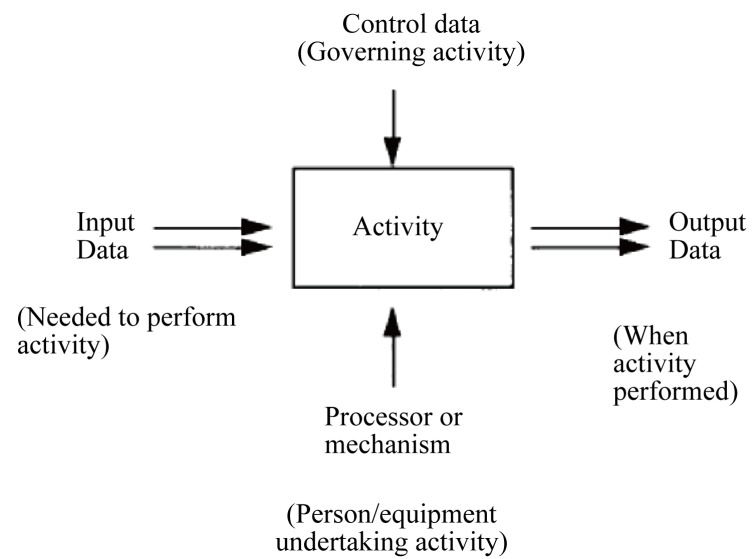

Figure 4. The structure of the process cost model [25].

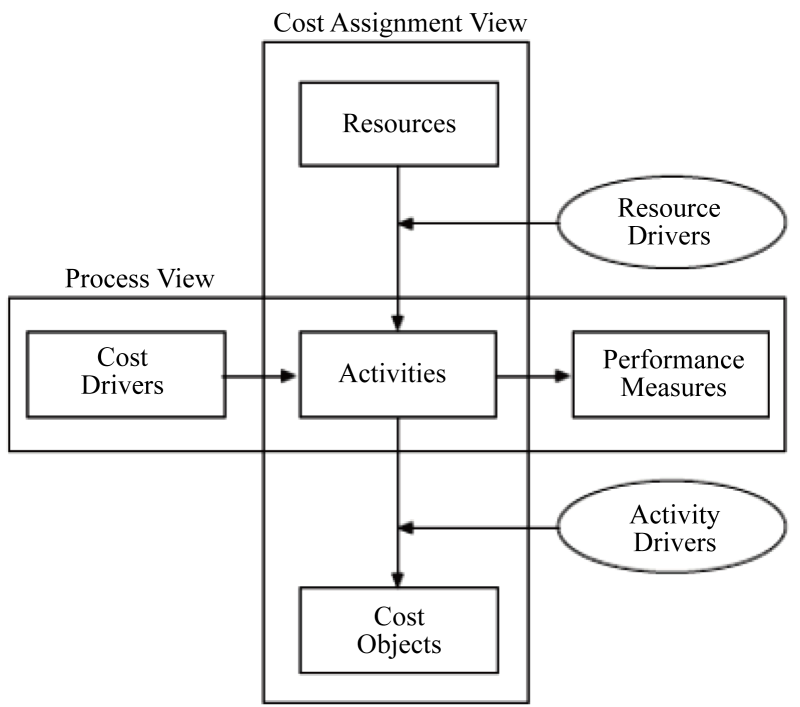

Figure 5. An example of ABC model [25]. 
There are many models which are not included in the above table. For example: Poor Quality Cost (PQC) model introduced by Harrington's in 1987, Accounting CoQ model proposed by Godfrey-Pasewark [36] in 1988 which represents a CoQ model from accounting point of view, Carr's service model developed in 1992, Miller and Morris profit based CoQ model developed in 2000, Capital Budgeting model introduced by (Beruvides and Chiu) in 2003, that can be used successfully as well.

\section{Incorporating CoQ in SCND}

In recent years, there has been a growing interest of the importance of incorporating the CoQ into the Supply Chain Network Design SCND which is considered one of the problems included in Supply Chain Management (SCM).

The challenge in global SCM is the design and the conception of a network considering the interactions among different entities of the Supply Chain, as well as external performance measures such as CoQ that must be integrated into SCND modeling.

As shown in Figure 6, a Supply Chain Network can be presented by a directed graph. The nodes of this graph represent the different entities of the SC such as suppliers, manufacturing plants and customers. The SCN is engineered by selecting a network that optimizes some performance measures such as transportation cost, quality cost, quantity, etc.

Table 1. CoQ models and categories (Vaxevanidis et al., 2008).

\begin{tabular}{|c|c|c|c|}
\hline Model & Cost category & Orientation & Example of publications \\
\hline P-A-F Models & Prevention-Appraisal-Failure & Activity-oriented & $\begin{array}{l}\text { Feigenbaum [2]; Burgess [28]; Dale [29]; } \\
\text { Chang et al. [30]; Bottorff [5]. etc. }\end{array}$ \\
\hline Opportunity Cost Models & P-A-F + Opportunity costs & ----- & $\begin{array}{l}\text { Juran [1]; Ansari [31]; Carr [21]; } \\
\text { Sandoval-Chavez [12]. etc. }\end{array}$ \\
\hline Process Cost Models & $\begin{array}{l}\text { Conformance }+ \\
\text { Non conformance }\end{array}$ & Process-oriented & $\begin{array}{l}\text { Ross [23]; Marsh [24]; Crossfield and Dale [32]; } \\
\text { Goulden and Rawlins [33]. etc. }\end{array}$ \\
\hline ABC Models & $\begin{array}{l}\text { Value Added + } \\
\text { Non-Value Added }\end{array}$ & Activity-oriented & $\begin{array}{l}\text { Cooper and Kaplan [26]; Jorgenson and Enkerlin [34]; } \\
\text { Dawes and Siff [35]; Tsai [27] etc. }\end{array}$ \\
\hline
\end{tabular}

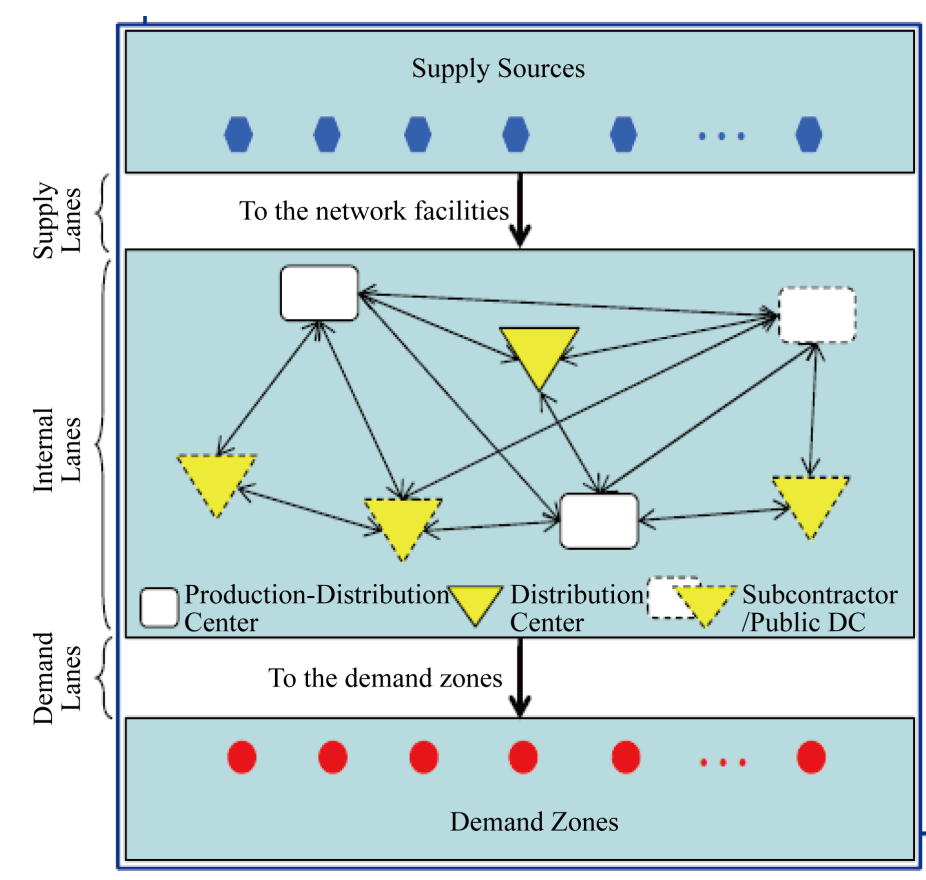

Figure 6. An example of supply chain network model [37]. 
The supply chain design is a strategic configuration of the supply chain and a key factor that influence tactical and operational levels, and therefore has a long lasting impact on the firms that makes the supply chain network design problem of an extreme importance.

SCND problems cover wide range of formulations ranged from simple single product type and linear deterministic models to complex multi-product non-linear stochastic ones.

Such models are of large scale and require strong computational power [38]. The first work concerning SCND was developed by Geoffrion and Graves [39] that presented a SCND for optimizing the flow of finished products from plants to distribution centers.

Breitman [40] developed for General Motors a SCND model considering the quantities of products, the selection of manufacturing plants to produce and the market objective. Camm et al. [41] presented a mathematical model analyzing the Supply Chain at Procter and Gamble's (P\&G's) in order to improve the efficiency of all work processes and to eliminate non value added costs. In 1998, Beamon [42] presented a literature review of supply chain modeling. He classified Supply Chain Models into four categories:

Analytical Deterministic Models: are models that do not include elements of randomness;

Analytical Stochastic Models: or probabilistic models are one which incorporates some aspect of random variation;

Economic Models: are simplified frameworks designed to illustrate complex processes, using mathematical techniques;

Simulation Models: are a mathematical business models which combine both mathematical and logical concepts that tries to emulate a real life system through use of computer software.

We summarize in Table 2, the publications developing each category of these models.

A difficult task in SCND is the choice of the appropriate performance measure. A performance measure is categorized as quantitative and qualitative and used to evaluate the effectiveness of a model, and to design alternative models.

Among qualitative performance measure: the customer satisfaction, flexibility, and effective risk management. The quantitative performance measures: cost minimization, sales or profit maximization, fill rate maximization, customer response time minimization, lead time minimization, etc. [8]. However, the SCM design and planning is usually involving trade-offs among different goals.

The Cost of Quality (CoQ) is considered as a key performance measurement in SCND that translates poor quality into monetary terms for managers. It can be measured, controlled and analyzed to attain a high level of quality at a minimum cost in order to reach customers satisfaction.

Several studies have been conducted in this direction to ensure quality in SC. Das [51] proposed a strategic supply chain model that allows managers to assure product quality and safety and prevent expensive product recall. Srivastava [4] measures CoQ in monetary terms using PAF model. Ramudhin et al. [38] also introduced a model integrating the Cost of Quality (CoQ) into the supply chain network and found that incorporating COQ in supply chain network design will ensure the lowest overall cost, and reduce the probability of defects of approximately 16\%. Castillo-Villar et al. [10] developed a mathematical model incorporating CoQ in Supply Chain Network (SCN). They studied the impact of fraction defective and inspection error rate at the manufacturer on total CoQ and quality level.

To structure the literature review of SCND problems and to show the difference of this paper form others, we present a state-of-the-art to review the existing works on the SCND problem in terms of the network structure and the modeling approach. The notations used for these models are given in Table 3.

\section{Table 2. Models of SCND categories [38].}

\begin{tabular}{ll}
\hline \multicolumn{1}{|c}{ Model category } & \multicolumn{1}{c}{ Example of publication developing the model } \\
\hline Analytical Deterministic Models & Cohen and Lee [43]; Arntzen et al. [44]; Voudouris [45]; Camm et al. [41] \\
Analytical Stochastic Models & Cohen and Lee [43]; Svoronos and Zipkin [46]; Lee and Billington [47]; Pyke and Cohen [48] \\
Economic Models & Christy and Grout [49] \\
Simulation Models & Towill [50] \\
\hline
\end{tabular}


Table 3. Modeling approach codes.

\begin{tabular}{|c|c|c|}
\hline Category & Detail & Code \\
\hline \multirow{7}{*}{ Objectives of models } & Total cost & $\mathrm{C}$ \\
\hline & Cost of Quality & CoQ \\
\hline & Profit & $\operatorname{Pr}$ \\
\hline & Robustness & Ro \\
\hline & Delivery period & $\mathrm{Dp}$ \\
\hline & Financial risk & $\mathrm{Fr}$ \\
\hline & Responsiveness (service level) & $\operatorname{Re}$ \\
\hline \multirow{9}{*}{ Decisions of models } & Location/allocation & $\mathrm{La}$ \\
\hline & Demand satisfaction & Ds \\
\hline & Transportation values & $\mathrm{Tv}$ \\
\hline & Ratio Defect & $\mathrm{Rd}$ \\
\hline & Inspection error rate & Ir \\
\hline & Quantity & $\mathrm{Q}$ \\
\hline & Facility Capacity & Fc \\
\hline & Number of periods & $\mathrm{T}$ \\
\hline & Number of suppliers & $\mathrm{J}$ \\
\hline \multirow{9}{*}{ Features of models } & Period & \\
\hline & Multi-period & MP \\
\hline & Single-period & SP \\
\hline & Product & \\
\hline & Multi-product & MPr \\
\hline & Single-product & $\mathrm{SPr}$ \\
\hline & Parameters & \\
\hline & Deterministic & $\mathrm{D}$ \\
\hline & Stochastic & $\mathrm{S}$ \\
\hline
\end{tabular}

Remark: As shown in Table 4, a large part of SCND problems is deterministic and involves simultaneous optimization of problems with at least two objective functions which are conflicting (ex: max profit and min costs). A smaller part is associated with optimizing supply chain considering the cost of quality.

\section{Optimization Techniques}

While the majority of SCND models involve simultaneous optimization with at least two objective functions, Evolutionary techniques such as Genetic Algorithms (GA), ant colony optimization (ACO) and Simulated Annealing (SA) for supply chain optimization, have been applied in the SCND due to likely to deal with highly nonlinear, multidimensional engineering problem. This generally justifies the big interest of using evolutionary algorithms to solve multi-objective optimization problems [9] [70]. In our study we will present a review of SA and GA applied to solve SCND Problems. Yann, Patrick [71] detailed these tools and techniques of optimization as shown in Figure 7. 
Table 4. Modeling features of the reviewed works.

\begin{tabular}{|c|c|c|c|c|c|}
\hline References & CoQ incorporated? & Decison variables & Features of model & Model objectives & Optimization method \\
\hline [42] & No & $\mathrm{La}, \mathrm{Tv}$ & SP, MPr, S & $\mathrm{C}, \mathrm{Re}$ & $\varepsilon$-constraint method \\
\hline [38] & Yes & Rd, Q & SPr, MP, S & CoQ, C & LINGO \\
\hline [51] & No & $\mathrm{La}, \mathrm{Fc}$ & SPr, MP, S & $\operatorname{Pr}$ & LINGO \\
\hline [52] & No & Q, Ds, La & MPr, MP, S & $\mathrm{C}$ & Weighting Method \\
\hline [53] & No & $\mathrm{La}, \mathrm{Tr}, \mathrm{Fc}$ & SPr, MP, S & Pr, Re & $\varepsilon$-constraint method \\
\hline [54] & Yes & Q & MPr, MP, S & CoQ, V & Differential Evolution Algorithm \\
\hline [55] & No & Q, Ds, Tv & Spr, Sp, D & C, Dp, Re & LINGO \\
\hline [56] & No & La, Ts & SPr, Sp, D & $\mathrm{C}$ & Decomposition methods \\
\hline [57] & No & L, Ts & SPr, Sp, D & $\mathrm{C}$ & CPLEX \\
\hline [58] & No & Fc, Q, Tv & MPr, MP, S & $\mathrm{C}$ & LINGO \\
\hline [59] & No & Q, La, Ds & Mpr, Mp, S & $\mathrm{C}$ & Fuzzy optimisation model \\
\hline [60] & Yes & Q, Fc & SPr, MP,D & CoQ & Gradient search matlab 7.0 \\
\hline [61] & No & Ds, Fc & MPr, Sp, D & $\mathrm{C}$ & Geographic Information System (GIS) \\
\hline [62] & Yes & Tv, La & SPr, MP, D & CoQ, Pr & Simulated Annealing (SA) \\
\hline [63] & Yes & La, Tr, Fc & SPr, SP, D & CoQ, Re & Simulated Annealing (SA) \\
\hline [23] & No & Tr, Q & SPr, SP, D & $\mathrm{C}$ & Simulated Annealing + Tabu Search \\
\hline [64] & Yes & $\mathrm{La}, \mathrm{Tv}$ & SPr, MP, D & CoQ, Pr & Algorithmes génétiques (GA) \\
\hline [8] & No & $\mathrm{Q}$ & SPr, SP,D & C, Re, V & Genetic Algorithm (GA) \\
\hline [17] & Yes & Dp, Q & Spr, Sp, D & CoQ & Genetic Algorithm (GA) \\
\hline [65] & No & $\mathrm{Q}$ & SPr, MP, D & $\mathrm{C}$ & Genetic Algorithm (GA) \\
\hline [66] & No & Q & MPr, Mp, S & C & $\begin{array}{l}\text { hGA = GA + PS } \\
\text { (genetic algorithm + pattern search technique) }\end{array}$ \\
\hline [67] & No & $\mathrm{Tv}, \mathrm{La}$ & Mpr, Sp, D & $\mathrm{C}$ & Genetic Algorithm (GA) \\
\hline [10] & Yes & Tv, Q & SPr, SP, S & CoQ, Pr & Genetic Algorithm (GA) \\
\hline [68] & No & Q, La & Spr, Sp, D & Dp, C & Genetic Algorithm (GA) \\
\hline [69] & No & $\mathrm{Q}, \mathrm{T}, \mathrm{J}$ & MPr, MP, D & C, $\operatorname{Pr}$ & Genetic Algorithm (GA) \\
\hline
\end{tabular}

\subsection{Simulated Annealing}

Simulated annealing was proposed by Kirkpatrick [72]. It is a nature-inspired method which is adopted from the process of gradual cooling of metal in nature [73]. It works by emulating the physical process whereby a solid is slowly cooled so that when eventually its structure is frozen. SA is a stochastic search technique, which has been designed for guiding search procedure to escape from the trap of local optimality. The first algorithm was developed by Collins et al. [74] to solve optimization problems with continuous variables. The basic elements of simulated annealing (SA) are described in the flowchart as follows (Figure 8).

\subsection{Review of SA Application}

According to Jayaraman [62], the application of SA is very efficient for the complex problems of SC. For his PLOT (Production, Logistics, Outbound, Transportation) design system, the objective function aims to minimize fixed costs to open warehouses and cross-docks, the costs to transport products from warehouses to cross-docks and the costs to supply products from cross-docks to satisfy the customer demand. The SA algorithm has proven to be speed and efficient under a variety of experimental settings. 


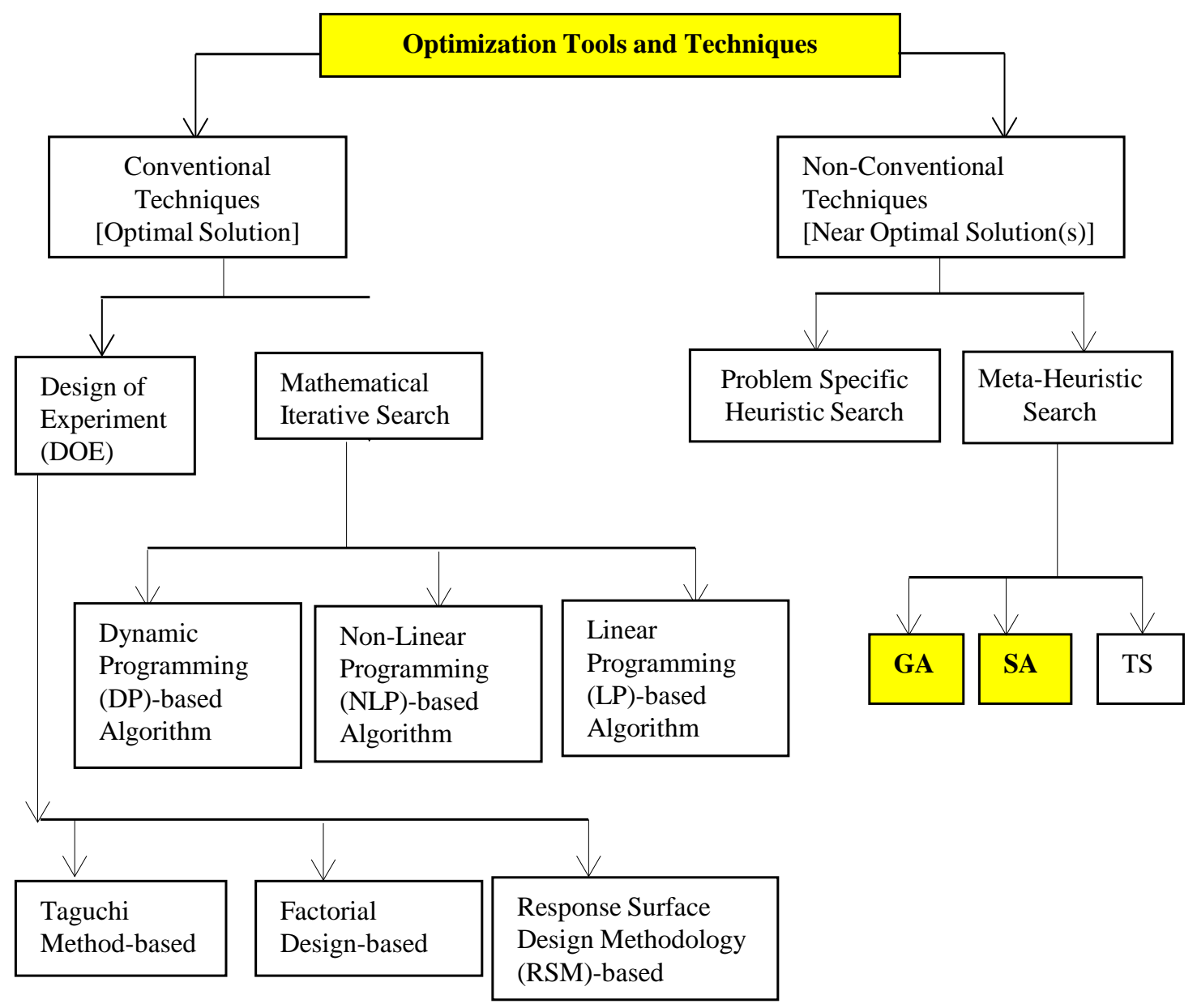

Figure 7. Conventional and non-conventional optimization tools and techniques [71].

Anthony Ross et al. [23] developed SA Algorithm to optimize the location of Cross Docks distribution centers in Supply Chain Network design, throw two objectives functions. The first function represents the strategic model and aims to minimize fixed costs, transport costs and carrying costs. The second function represents the executional model and used to minimize the cost to supply and to transport the products. The author integrated simulated annealing with both a Tabu search approach and a re-scaling approach and compared the two methods called TABU-SA and RESCALE-SA. The experimental study showed that TABU-SA provide better quality solutions in less time.

Pishvaee et al. [63] proposed an optimization methodology for a reverse logistics network design using SA. The settings of SA parameters in his study are as follows: initial temperature $=100$; frozen state $=0$; cooling rate $=\mathrm{cr} ; \mathrm{k}=7$. The proposed model helps to find locations, the number of collection centers and also the quantity of transportation between facilities. The SA is coded in MATLAB 7.0, and the results were compared with results obtained by LINGO 8.0 software. LINGO is based on branch-and-bound algorithm to solve the problems and find the global optimal solution. The performance of the SA algorithm was evaluated under different parameters of SA.

Castello Villar et al. [76] used SA as a heuristic procedure to solve a combinatorial optimization problem in Supply Chain Design incorporating the Cost of Quality.

The model developed aims to choice the entities of SC that maximize the profit, and minimizes the total CoQ in determining the error rate at inspection and the defective ratio at manufacturing. The settings of SA parameters in his study are as follows: Cooling Rate $(\alpha)$ : low $=0.7$, high $=0.9$; Initial Temperature (To): low $=400$, high $=500$; Prob. of mutation: low $=0.2$, high $=0.8$. The study shows that problem instances of realistic size can be solved quickly by using SA. 


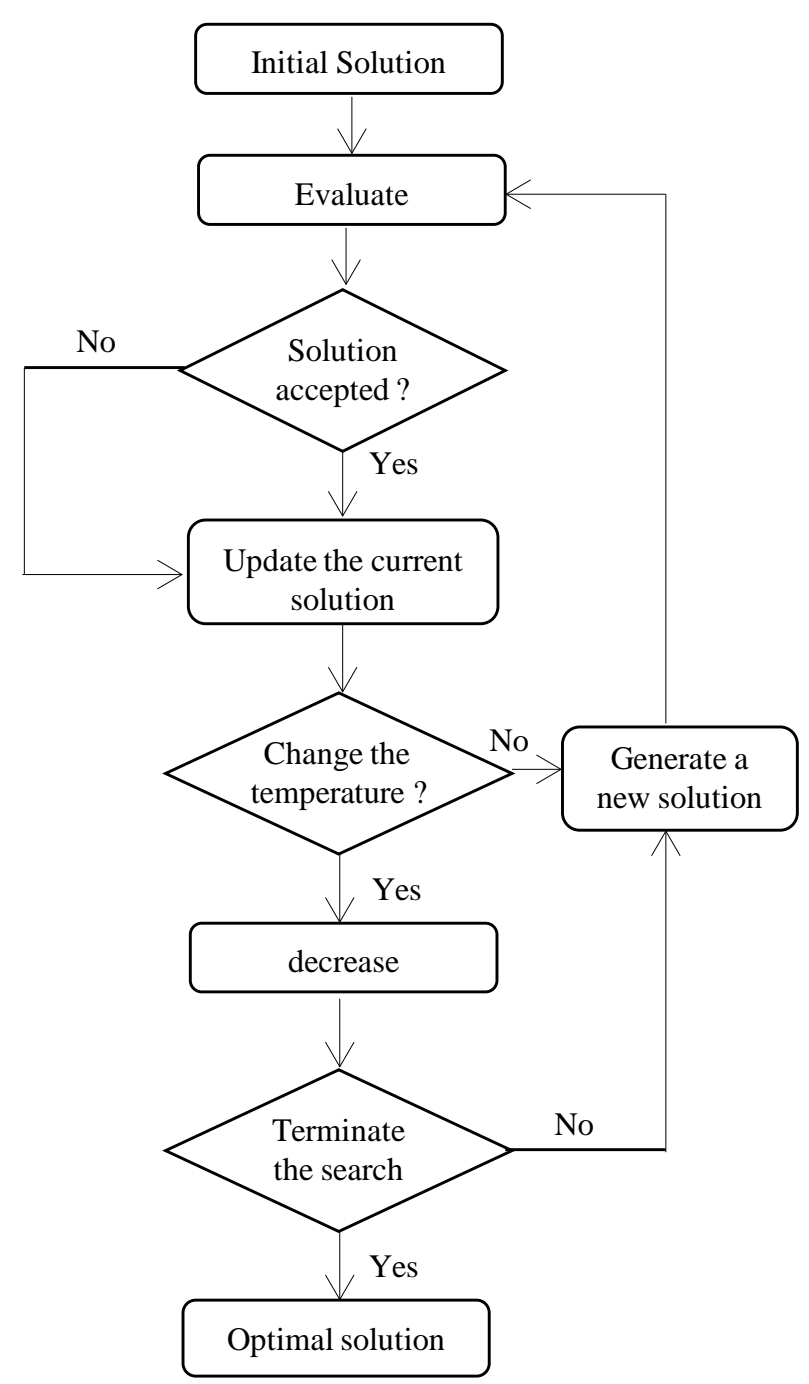

Figure 8. SA optimization flowcharts [75].

We summarize in Table 5, the references developing a simulated annealing based solution approach.

Remark: SA gives finer results and his powerfulness originates in the good selection and annealing technique. But there is little research into using the simulated annealing method for optimization SCND to minimize the CoQ. Except the authors obviously treated, there is no use of SA in the logistics network.

\subsection{Genetic Algorithms}

Genetic algorithms (GAs) are evolutionary algorithms which were developed by John Holland [77] and his collaborators in the 1970s, inspired by Darwin's theory about evolution. The Algorithm is started with a set of solutions called initial population. This population is encoded as arrays of bits or character strings (chromosomes). The essence of genetic algorithms involves the use of genetic operators like crossover, recombination, mutation and selection to obtain a new population with the hope that the new population will be better than the old one. This is repeated until some condition is satisfied.

The procedure of Genetic Algorithm (GA) is described in the flowchart as follows (Figure 9).

\subsection{Review of GA Application}

Seyed Hamid et al. [68] used GA to find a near optimum solution for his tri objective integer non linear model. The first objective function is considered to minimize the waiting times of products, the second one tries to 
Table 5. Optimization of SCND using SA.

\begin{tabular}{ccccc}
\hline References & Cooling rate & T0 & Pob of moving & Size of neighborhood \\
\hline$[76]$ & $0.7-0.9$ & $400-500$ & $0.2-0.8$ & $3 / 2 / 2$ to $9 / 4 / 7$ \\
{$[62]$} & $0.2-0.95$ & NS* & NS & $5 / 10 / 30 / 2$ to $5 / 15 / 75 / 3$. \\
{$[63]$} & $0.03-0.15$ & $70-100$ & NS & NS \\
{$[23]$} & $\alpha$ & Tp & NS & $75 / 15 / 5 / 3$ to $30 / 10 / 5 / 2$ \\
\hline
\end{tabular}

*NS: Not specified.

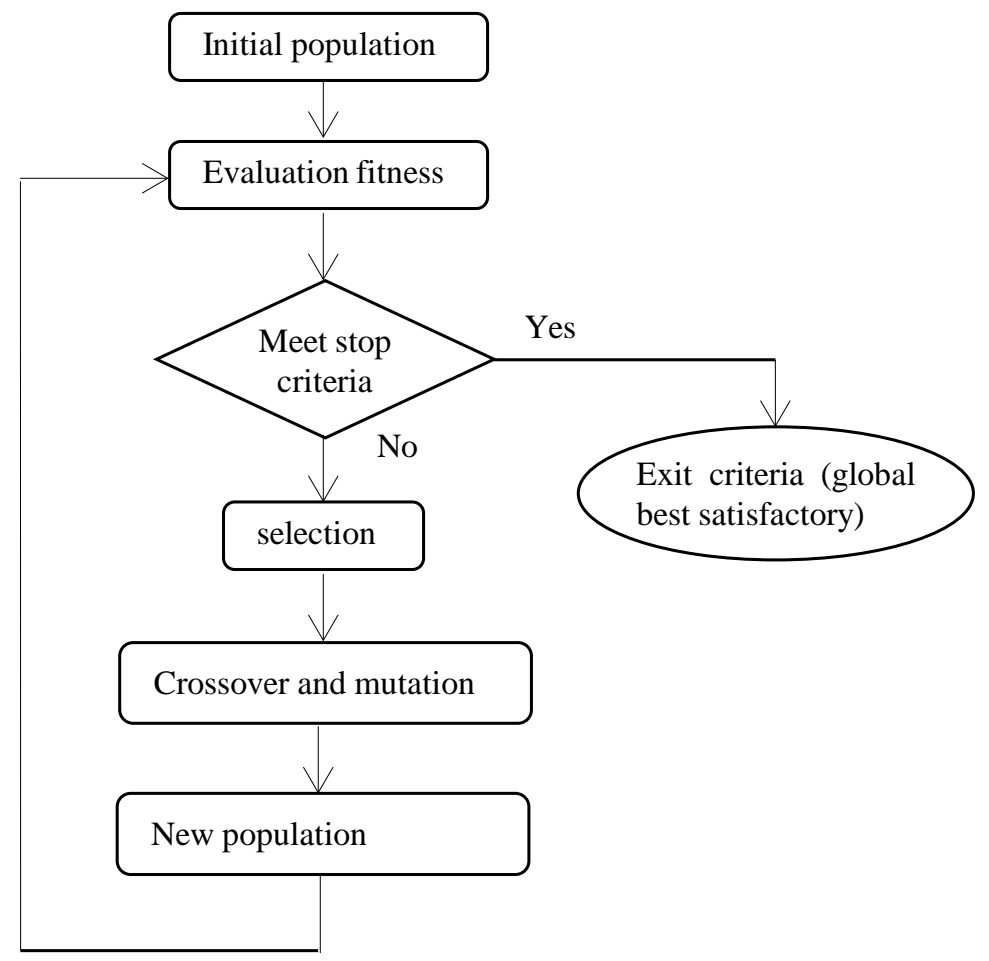

Figure 9. GA optimization flowcharts [78].

maximize the minimum reliability of machines at the workstations, the third objective consists on minimizing the mean idle time of the machines. He developed and compared tow solutions procedures: NSGA-II (Nondominated sorting genetic algorithm) and NRGA (Non-dominated ranked genetic algorithm) to solve the model, and found that NSGA-II was the better one capable to obtain suitable fronts. S. Bozorgirad et al. [67] proposed a Route Based Genetic Algorithm (RBGA) with Edge-and-vertex encoding method for his multi source multi product multistage logistics network to minimize the total logistic cost, and compared it with the solution obtained using standard GA with penalty method, and using numerical experiment, he found that the solution obtained using RB-GA is more acceptable.

Chandrasekaran et al. [79] proposed a GA based approach to optimize supply chain network by reducing operating costs. He considered a four echelon system composed by suppliers, plants, distribution centers and retailers. The GA parameters are set with the following values where sample size $=20$, crossover $=0.2$, mutation $=0.02$ and number of generations $=50$. The Software used: MATLAB 7.5. The experimental results showed the effectiveness of GA to provide an optimal solution within few minutes while running on a standard PC. Rezaei J. et al. [69] employed GA technique to optimize a multiple products and multiple suppliers supply chain model. The objective function consists on maximizing the total profit for the whole supply chain, in order to determine the products to order, the quantities, the suppliers, and the periods to order. The results were compared with 
Lindo results. GA method gives more solutions with higher level information. Altiparmak et al. [8] suggested a solution procedure based on GA to solve Supply Chain Network design problem. The authors presented a generalized mathematical programming model as a multi-objective mixed-integer non-linear programming model to optimize three objective functions: minimizing the total cost, maximizing the service level and maximizing the capacity utilization balance. The proposed algorithm was coded with $\mathrm{C}++$ programming language considering following parameters: population size $=400$; crossover rate $=0.5$, mutation rate $=0.7$, number of generation $=$ 500 and number of generations $=10$.

Reza Farahani et al. [9] developed a genetic algorithm to optimize the total cost and service level in a supply chain. Lin et al. [80] compared flexible supply chains and traditional supply chains with a hybrid genetic algorithm and mentioned advantages of flexible ones. Also, several studies have been developed about optimization SCND using GA by different researchers. Gen and Syarif [64] considered the total cost as an objective function in their Supply Chain Network Design, the problem was solved by a hybrid Genetic Algorithm. Sourirajan et al. [81] developed a multi objective stochastic programming approach. They considered a two echelon supply chain. The objective function is to minimize safety stock costs and to locate distribution centers in the network. They proposed a solution method based on genetic algorithms to solve the model. Chan and Chung [30] proposed a SCND for minimizing the costs and the total delivery time which were considered as objective functions. They proposed a genetic algorithm to solve the multi-objective problem.

Other studies were developed in optimizing SCND using GA, are summarized in Table 6. The following notations are used to represent the parameters of the GA: pop_size: population size; Pm: mutation rate for chromosomes; Pc: crosseover rate for chromosomes; Max_gen: maximum generation.

GA is known for its easy concept. The effectiveness of this algorithm is tested for various real life problems and is found to be very effective. Many comparisons were set up by authors between GA and other methods shows that we can trust the heuristics based GA as a solution methodology especially for the larger problem sizes. GA performs very well in terms of both quality of solutions obtained and computational time.

\section{Conclusion and Future Directions}

This article summarizes last research concerning the models of SC taking into account quality measures. There is a surprising lack of references analyzing and developing SCND incorporating the CoQ in spite of its major contribution in assisting firms to improve their profitability and quality simultaneously. Optimization techniques are also reviewed; there have been many researches into using evolutionary algorithms such as GA and SA which are very powerful searching algorithms that give good results in various optimization fields.

\begin{tabular}{|c|c|c|c|c|c|}
\hline References & Pc & $\mathrm{Pm}$ & Representation & Pop size & Max gen \\
\hline [64] & 0.4 & 0.2 & Vertex Encoding & 25 to 300 & 750 to 10000 \\
\hline [82] & 0.4 & 0.2 & Vertex Encoding & 10 to 75 & 1000 to 5000 \\
\hline [8] & 0.5 & 0.7 & Priority Based-Encoding & 400 & 500 \\
\hline [65] & NS* & 0.5 & Edge Based-Encoding & 50 & 200 \\
\hline [66] & 1 & 0.25 & Binary & 160 & 20 \\
\hline [67] & NS & NS & Edge-and-Vertex Encoding & NS & NS \\
\hline [10] & 0.01 & 0.95 & Binary & 120 & 25 \\
\hline [68] & 0.65 & 0.15 & Matrix & 40 & NS \\
\hline [69] & NS & 0.1 & NS & 100 & NS \\
\hline [63] & 0.5 & 0.7 & Matrix & 30 & NS \\
\hline
\end{tabular}

*NS: Not specified. 
Further research in providing a good method for identification and measurement of quality costs, and optimizing SC incorporating this method using evolutionary algorithms should be conducted, that can allow target action for reducing CoQ and saving money for enterprises.

\section{References}

[1] Juran, J.M. (1951) Quality Control Handbook. McGraw-Hill, New York.

[2] Feigenbaum, A. (1957) The Challenge of Total Quality Control. Industrial Quality Control, 13, 17-23.

[3] Machowski, F. and Dale, B.G. (1998) Quality Costing: An Examination of Knowledge, Attitudes and Perceptions. Quality Management Journal, 5, 84-95.

[4] Srivastava, S.K. (2008) Towards Estimating Cost of Quality in Supply Chains. Total Quality Management \& Business Excellence, 19, 193-208. http://dx.doi.org/10.1080/14783360701600605

[5] Bottorff, D.L. (1997) CoQ Systems: The Right Stuff. Quality Progress, 30, 33-35.

[6] Crosby, P. (1984) Quality without Tears: The Art of Hassle Free Management. McGraw-Hill, New York.

[7] Sower, V.E. and Quarles, R. (2007) Cost of Quality Usage and Its Relationship to Quality System Maturity. International Journal of Quality \& Reliability Management, 24, 121-140. http://dx.doi.org/10.1108/02656710710722257

[8] Altiparmak, F., Gen, M., Lin, L. and Paksoy, T. (2006) A Genetic Algorithm Approach for Multi-Objective Optimization of Supply Chain Networks. Computers \& Industrial Engineering, 51, 196-215. http://dx.doi.org/10.1016/j.cie.2006.07.011

[9] Farahani, R.Z. and Elahipanah, M. (2008) A Genetic Algorithm to Optimize the Total Cost and Service Level for Just-in-Time Distribution in a Supply Chain. International Journal of Production Economics, 111, 229-243. http://dx.doi.org/10.1016/j.ijpe.2006.11.028

[10] Castillo-Villar, K.K., Smith, N.R. and Herbert-Acero, J.F. (2014) Design and Optimization of Capacitated Supply Chain Networks Including Quality Measures. Mathematical Problems in Engineering, 2014, Article ID: 218913. http://dx.doi.org/10.1155/2014/218913

[11] Freeman, J.M. (2008) The Case for Quality Costing Simulation. Journal of Total Quality Management, 20, 476-487.

[12] Sandoval-Chavez, D.A. and Beruvides, M.G. (1998) Using Opportunity Costs to Determine the Cost of Quality: A Case Study in a Continuous-Process Industry. Engineering Economist, 43, 107-124. http://dx.doi.org/10.1080/00137919808903192

[13] Schiffauerova, A. and Thomson, (2006) A Review of Research on Cost of Quality Models and Best Practices. International Journal of Quality and Reliability Management, 23, 647-669. http://dx.doi.org/10.1108/02656710610672470

[14] Porter, L.J. and Rayner, P. (1992) Quality Costing for Total Quality Management. International Journal of Production Economics, 27, 69-81. http://dx.doi.org/10.1016/0925-5273(92)90127-S

[15] Campanella, J. (1990) Principles of Quality Costs: Principles, Implementation, and Use. 2nd Edition, ASQC Quality Costs Committee, Milwaukee.

[16] Stefano, A.S., Valentina, C., Lorenzo, T., Nils, L. and Jutta, G. (2015) A Logistic Network to Harmonise the Development of Local Food System with Safety and Sustainability. International Journal of Integrated Supply Management, 9, 307-328. http://dx.doi.org/10.1504/IJISM.2015.070530

[17] Ozgur, A. and Huseyin, A. (2009) Cost of Quality Management: An Empirical Study from Turkish Marble Industry. Scientific Research and Essay, 4, 1275-1285.

[18] Fox, M.J. (1989) The Great Economic Quality Hoax. Quality Assurance, 15, 72-74.

[19] Price, F. (1984) Right First Time. Gower, Aldershot.

[20] Tatikonda, L.U. and Tatikonda, R.J. (1996) Measuring and Reporting the Cost of Quality. Production and Inventory Management Journal, 37, 1-7.

[21] Carr, L.P. (1992) Applying Cost of Quality to a Service Businesses. Sloan Management Reviews, 33, $72-77$.

[22] Albright, T.L. and Roth, H.P. (1992) The Measurement of Quality Costs: An Alternative Paradigm. Accounting Horizons, 6, 15-27.

[23] Ross, D.T. (1977) Structured Analysis (SA): A Language for Communicating Ideas. IEEE Transactions on Software Engineering, 3, 16-34. http://dx.doi.org/10.1109/TSE.1977.229900

[24] Marsh, J. (1989) Process Modeling for Quality Improvement. Proceedings of the 2nd International Conference on Total Quality Management, London, 14-15 June 1989, 111-215.

[25] Vaxevanidis, N.M. and Petropoulos, G. (2008) A Literature Survey of Cost of Quality Models. Annals of Faculty of 
Engineering Hunedoara-Journal of Engeering, 6, 274-283.

[26] Cooper, R. and Kaplan, R.S. (1988) Measure Costs Right: Make the Right Decisions. Harvard Business Review, 66, 96-103.

[27] Tsai, W.H. (1998) Quality Cost Measurement under Activity-Based Costing. International Journal of Quality and Reliability Management, 15, 719-752. http://dx.doi.org/10.1108/02656719810218202

[28] Burgess, T.F. (1996) Modeling Quality-Cost Dynamics. International Journal of Quality \& Reliability Management, 13, 8-26. http://dx.doi.org/10.1108/02656719610116054

[29] Dale, B.G. and Plunkett, J.J. (1995) Quality Costing. 2nd Edition, Chapman and Hall, London.

[30] Chan, F.T.S. and Chung, S.H. (2004) A Multi-Criterion Genetic Algorithm for Order Distribution in a Demand Driven Supply Chain. International Journal Computer Integrated Manufacturing, 17, 339-351. http://dx.doi.org/10.1080/09511920310001617022

[31] Modarres, B. and Ansari, A. (1987) Two New Dimensions in the Cost of Quality. International Journal of Quality \& Reliability Management, 4, 9-20. http://dx.doi.org/10.1108/eb002886

[32] Crossfield, R.T. and Dale, B.G. (1990) Mapping Quality Assurance Systems: A Methodology. Quality and Reliability Engineering International, 6, 167-178. http://dx.doi.org/10.1002/qre.4680060303

[33] Goulden, C. and Rawlins, L. (1995) A Hybrid Model for Process Quality Costing. International Journal of Quality \& Reliability Management, 12, 32-47. http://dx.doi.org/10.1108/02656719510097499

[34] Jorgenson, D.M. and Enkerlin, M.E. (1992) Managing Quality Costs with the Help of Activity Based Costing. Journal of Electronics Manufacturing, 2, 47-55. http://dx.doi.org/10.1142/S0960313192000182

[35] Dawes, E.W. and Siff, W. (1993) Using Quality Costs for Continuous Improvement. ASQC Annual Quality Congress Transactions, 47, 810-816.

[36] Godfrey, J.T. and Pasewark, W.R. (1988) Controlling Quality Costs. Management Accounting, 69, 48-51.

[37] Walid, K. (2008) The Design of Robust Value Creating Supply Chain Networks: A Critical Review. Interuniversity Research Center on Enterprise Networks Logistics and Transportation-CIRRELET.

[38] Ramudhin, A., Alzaman, C. and Bulgak, A.A. (2008) Incorporating the Cost of Quality in Supply Chain Design. Journal of Quality in Maintenance Engineering, 14, 71-86. http://dx.doi.org/10.1108/13552510810861950

[39] Geoffrion A.M. and Graves, G.W. (1974) Multicommodity Distribution System Design by Benders Decomposition. Management Science, 20, 822-844. http://dx.doi.org/10.1287/mnsc.20.5.822

[40] Breitman, R.L. and Lucas, J.M. (1987) PLANETS: A Modeling System for Business Planning. Interfaces, 17, 94-106. http://dx.doi.org/10.1287/inte.17.1.94

[41] Camm, J.D., Chorman, T.E., Dill, F.A., Evans, J.R., Sweeney, D.J. and Wegryn, G.W. (1997) Blending OR/MS, Judgment, and GIS: Restructuring P\&G’s Supply Chain. Interfaces, 27, 128-142. http://dx.doi.org/10.1287/inte.27.1.128

[42] Sabri, E.H. and Beamon, B.M. (2000) A Multi-Objective Approach to Simultaneous Strategic and Operational Planning in Supply Chain Design. Omega, 28, 581-598. http://dx.doi.org/10.1016/S0305-0483(99)00080-8

[43] Cohen, M.A. and Lee, H.L. (1989) Resource Deployment Analysis of Global Manufacturing and Distribution Networks. Journal of Manufacturing and Operations Management, 2, 81-104.

[44] Arntzen, B.C., Brown, G.G., Harrison, T.P. and Trafton, L.L. (1995) Global Supply Chain Management at Digital Equipment Corporation. Interfaces, 25, 69-93. http://dx.doi.org/10.1287/inte.25.1.69

[45] Voudouris, V.T. (1996) Mathematical Programming Techniques to Debottleneck the Supply Chain of fine Chemical Industries. Computers and Chemical Engineering, 20, 1269-1274. http://dx.doi.org/10.1016/0098-1354(96)00219-0

[46] Svoronos, A. and Zipkin, P. (1991) Evaluation of One-for-One Replenishment Policies for Multi-Echelon Inventory Systems. Management Science, 37, 68-83. http://dx.doi.org/10.1287/mnsc.37.1.68

[47] Lee, H.L. and Billington, C. (1993) Material Management in Decentralized Supply Chains. Operations Research, 41, 835-847. http://dx.doi.org/10.1287/opre.41.5.835

[48] Pyke, D.F. and Cohen, M.A. (1993) Performance Characteristics of Stochastic Integrated Production-Distribution Systems. European Journal of Operational Research, 68, 23-48. http://dx.doi.org/10.1016/0377-2217(93)90075-X

[49] Christy, D.P. and Grout, J.R. (1994) Safeguarding Supply Chain Relationships. International Journal of Production Economics, 36, 233-342. http://dx.doi.org/10.1016/0925-5273(94)00024-7

[50] Towill, D.R. (1991) Supply Chain Dynamics. International Journal of Computer Integrated Manufacturing, 4, 197208. http://dx.doi.org/10.1080/09511929108944496

[51] Das, K. (2011) A Quality Integrated Strategic Level Global Supply Chain Model. International Journal of Production 
Research, 49, 5-31. http://dx.doi.org/10.1080/00207543.2010.508933

[52] Alborzi, F., Vafaei, H., Gholami, M.H. and Esfahani, M.M.S. (2011) A Multi-Objective Model for Supply Chain Network Design under Stochastic Demand. World Academy of Science, Engineering and Technology, 5, 1651-1655.

[53] Reza, Z.F. and Mahsa, E. (2007) A Genetic Algorithm to Optimize the Total Cost and Service Level for Just-in-Time Distribution in a Supply Chain. International Journal of Production Economics, 111, 229-243.

[54] Shahrooz, S., Payam, C. and Ahmad, A. (2013) Designing an Integrated Multi-objective Supply Chain Network Considering Volume Flexibility. Proceedings of the World Congress on Engineering and Computer Science, Vol. II, San Francisco, 23-25 October 2013.

[55] Paksoy, T., Özceylan, E. and Weber, G.-W. (2010) A Multi-Objective Mixed Integer Programming Model For Multi Echelon Supply Chain Network Design and Optimization. Selçuk University, Department of Industrial Engineering, Campus, Konya, Turkey.

[56] Rui, T.S., Songsong, L., Lazaros, G.P. and Nilay, S. (2011) Global Supply Chain Planning for Pharmaceuticals. Chemical Engineering Research and Design, 8, 2396-2409.

[57] Fleischmann, M. and Beullens, P. (2011) Reverse Logistics Network Structures and Design. Faculty of Business Admin Erasmus University Rotterdam, Netherlands.

[58] Bennekrouf, M., Mtalaa, W., Boudhar, F. and Sari, Z. (2011) A Dynamic Model for the Design of Green Logistic Networks. Proceedings of the 41st International Conference on Computers \& Industrial Engineering, Los Angeles, 23-25 October 2011, 62-67.

[59] Anil J., Kuldip S.S. and Sachin S.P. (2015) Network Design and Optimization for Multi-Product, Multi-Time, Multiechelon Closed-Loop Supply Chain under Uncertainty. The 22nd CIRP Conference on Life Cycle Engineering, 29, 656661.

[60] Asil Bulgak, A., Alzaman, C. and Ramudhin, A. (2008) Incorporating the Cost of Quality in Supply Chain Design. Portland International Conference on Management of Engineering \& Technology, Cape Town, 27-31 July 2008, 16501655. http://dx.doi.org/10.1109/picmet.2008.4599784

[61] Yasamann, K. and Joseph, S. (2016) An Optimization Model for Downstream Petroleum Supply Chain Incorporating Geographic Information System (GIS). International Journal of Integrated Supply Management, 10, 151-172. http://dx.doi.org/10.1504/IJISM.2016.077049

[62] Jayaraman, V. and Ross, A. (2003) A Simulated Annealing Methodology to Distribution Network Design and Management. European Journal of Operational Research, 144, 629-645. http://dx.doi.org/10.1016/S0377-2217(02)00153-4

[63] Pishvaee, M.S., Farahani, R.Z. and Dullaert, W. (2010) A Memetic Algorithm for Bi-Objective Integrated Forward/ Reverse Logistics Network Design. Computers \& Operations Research, 37, 1100-1112. http://dx.doi.org/10.1016/j.cor.2009.09.018

[64] Syarif, A., Yun, Y.S. and Gen, M. (2002) Study on Multi-Stage Logistics Chain Network: A Spanning Tree-Based Genetic Algorithm Approach. Computers \& Industrial Engineering, 43, 299-314. http://dx.doi.org/10.1016/S0360-8352(02)00076-1

[65] Fulya, A., Mitsuo, G.B., Lin, L.B. and Ismail, K. (2009) A Steady-State Genetic Algorithm for Multi-Product Supply Chain Network Design. Computers \& Industrial Engineering, 56, 521-537. http://dx.doi.org/10.1016/j.cie.2007.05.012

[66] Abbas, H., Hussein, M. and Etman, M. (2011) A Hybrid Genetic Algorithm Approach for Optimizing Dynamic Multi-Commodity Supply Chains. Proceedings of the 41st International Conference on Computers \& Industrial Engineering, Los Angeles, 23-25 October 2011, 154-159.

[67] Seyedyaser-Mohammad, B., Desa, I. and Wibowo, A. (2012) Genetic Algorithm Enhancement to Solve Multi Source Multi Product Flexible Multistage Logistics Network. International Journal of Computer Science Issues, 9, 157-165.

[68] Seyed, H. and Reza, P. (2014) Two Metaheuristics to Solve a Multi-Item Multiperiod Inventory Control Problem under Storage Constraint and Discounts. The International Journal of Advanced Manufacturing Technology, 69, 1671-1684.

[69] Majid, R., Mahdi, B. and Reza, T.M. (2013) A New Multi-Objective Stochastic Model for a Forward/Reverse Logistic Network Design with Responsiveness and Quality Level. Applied Mathematical Modeling, 37, 328-344. http://dx.doi.org/10.1016/j.apm.2012.02.032

[70] Pinto, E.G. (2004) Supply Chain Optimization Using Multi-Objective Evolutionary Algorithms. Department of Industrial and Manufacturing Engineering, the Pennsylvania State University, University Park, 15-26.

[71] Collette, Y. and Siarry, P. (2002) Optimisation Multiobjectif. Editions Eyrolles, Paris.

[72] Kirkpatrick, S., Gelatt, C.D. and Vecchi, M.P. (1983). Optimization by Simulated Annealing. Science, 220, 671-680. http://dx.doi.org/10.1126/science.220.4598.671

[73] Metropolis, N., Rosenbluth, A.W., Rosenbluth, M.N., Teller, A.H. and Teller, E. (1953) Equation of State Calculations by Fast Computing Machines. The Journal of Chemical Physics, 21, 1087-1092. 
http://dx.doi.org/10.1063/1.1699114

[74] Collins, N.E., Egelese, R.W. and Golden, B.L. (1988) Simulated Annealing-An Annotated Bibliography. American Journal of Mathematical and Management Sciences, 8, 209-307. http://dx.doi.org/10.1080/01966324.1988.10737242

[75] Eglese, R. (1990) Simulated Annealing: A Tool for Opeational Research. European Journal of Operational Research, 46, 271-281. http://dx.doi.org/10.1016/0377-2217(90)90001-R

[76] Castillo-Villar, K.K., Smith, N.R. and Simonton, J.L. (2012) The Impact of the Cost of Quality on Serial Supply-Chain Network Design. International Journal of Production Research, 50, 5544-5566. http://dx.doi.org/10.1080/00207543.2011.649802

[77] Holland, J. and Arbor, A. (1975) Adaptation in Natural and Artificial Systems. University of Michigan Press, Ann Arbor.

[78] Michel, G. and Jean-Yves, P. (2010) Handbook of Metaheuristics. International Series in Operations Research \& Management Science, Springer, Berlin.

[79] Sowmya Danalakshmi, C. Lecturer, Karpagam College of Engineering, Coimbatore-641032.

[80] Lin, L., Gen, M. and Wang, X. (2007) A Hybrid Genetic Algorithm for Logistics Network Design with Flexible Multistage Model. International Journal of Information Systems for Logistics and Management, 3, 1-12.

[81] Sourirajan, K., Ozsen, L. and Uzsoy, R. (2009) A Genetic Algorithm for a Single Product Network Design Model with Lead Time and Safety Stock Considerations. European Journal of Operational Research, 197, 599-608. http://dx.doi.org/10.1016/j.ejor.2008.07.038

[82] Syarif, A. (2005) Hybrid Genetic Algorithm for Multi-Time Period Production/Distribution Planning. Computers \& Industrial Engineering, 48, 799-809.

\section{Submit or recommend next manuscript to SCIRP and we will provide best service for you:}

Accepting pre-submission inquiries through Email, Facebook, LinkedIn, Twitter, etc.

A wide selection of journals (inclusive of 9 subjects, more than 200 journals)

Providing 24-hour high-quality service

User-friendly online submission system

Fair and swift peer-review system

Efficient typesetting and proofreading procedure

Display of the result of downloads and visits, as well as the number of cited articles

Maximum dissemination of your research work

Submit your manuscript at: http://papersubmission.scirp.org/ 